\title{
Preliminary report on antifungal activity of a Solanum nigrum extract against five mycotoxin-producing fungi
}

\author{
Mauro Musto* \\ University of Basilicata, School of Agricultural, Forestry, Food and Environmental Sciences, Viale dell'Ateneo Lucano, Potenza, Italy
}

\section{A B S TR A C T}

\begin{abstract}
Given the increased interest for the prevention and reduction of mycotoxin contamination, a research was conducted to evaluate whether an aqueous crude extract from Solanum nigrum lyophilized leaves was active against five mycotoxin-producing fungi. Alkaloids, tannins, flavonoids, saponins, and other bioactive compounds were found in the extract. Two in vitro antifungal assays were performed, the well diffusion and the paper disk diffusion tests. The results of both tests showed that the extract inhibited the growth of two out of five tested mycotoxin-producing fungi, with inhibition zones slightly lower than those of positive control. These preliminary findings confirm the antimicrobial activity of $S$. nigrum, and encourage further researches on this plant to develop natural agents against mycotoxigenic fungi in order to replace synthetic pesticides.
\end{abstract}

Key words: Antifungal activity; biopesticides; mycotoxin-producing fungi; plant extracts; Solanum nigrum

\section{INTRODUCTION}

In past decades, there has been an increasing interest toward some fungi belonging to the genera Aspergillus, Penicillium, Fusarium, and Alternaria. This interest is motivated by the fact that the occurrence of these fungi in foods and feeds may lead not only to significant economic losses, but may represent a health hazard to both humans and animals. This is mainly due to the production of some compounds from secondary metabolism process known as mycotoxins. It has been reported that more than 300 mycotoxins are currently known (Zain, 2011; Didwania, 2014), of which aflatoxins, ochratoxins, fumonisins, trichothecenes, and zearalenone are the most important ones (Pitt, 2000; CAST, 2003). These compounds can exert several toxic effects when ingested, from allergic responses to death. For instance, aflatoxins, which are produced by some Aspergillus species (Peraica et al., 1999; Richard, 2007; Didwania, 2014) have been defined as 'acutely toxic, immunosuppressive, mutagenic, teratogenic and carcinogenic compounds' (Peraica et al., 1999; p. 756). Ochratoxins, which are produced by some Aspergillus and Penicillium strains, are no less dangerous than aflatoxins. In particular, ochratoxin $A$ is the most toxic one, due to its nephrotoxic, immunosuppressive, carcinogenic and teratogenic activity (Peraica et al., 1999; Richard, 2007).

The presence of mycotoxins is strictly related to some aspects related to storage, environmental, and ecological conditions of foods and feeds. Therefore, mycotoxin contamination can occur at various stages (e.g. in the field, during storage and processing) in the food chain (Bennett \& Klich, 2003). Several biological, chemical and physical approaches have been proposed to reduce contamination levels in food and feeds, and, hence, to minimize human and animal exposure to mycotoxins (Varga \& Tóth, 2005; Kabak et al., 2006; Zain, 2011). Approaches like physical separation of contaminated commodities, microwave or sonic drying, or the use of chemical antifungal agents, are undoubtedly effective, although they have some inherent disadvantages related to the sustainability of the equipment and chemicals, reduction of the nutritional value of the foods, the presence of toxic derivatives in the treated product, etc. (Juglal et al., 2002; Varga \& Tóth, 2005; Kabak et al., 2006; Thembo et al., 2010).

A promising alternative approach is the use of plant extracts or plant phytochemical constituents for inhibiting fungal growth and, hence, to control mycotoxin contamination.

\footnotetext{
*Corresponding author:

Mauro Musto, University of Basilicata, School of Agricultural, Forestry, Food and Environmental Sciences, Viale dell'Ateneo

Lucano 10, 85100 Potenza, Italy, E-mail: mauro.musto@gmail.com
}

Received: 04 August 2015; $\quad$ Revised: 13 October 2015;

Accepted: 20 October 2015;

Published Online: 20 October 2015 
Previous studies (e.g. Juglal et al., 2002; Rasooli \& Abyaneh, 2004; Razzaghi-Abyaneh et al., 2008; Nguefack et al., 2009; Morcia et al., 2012) have found that essential oils from some aromatic plants were able to inhibit the growth of some Aspergillus, Fusarium, and Penicillium strains, all responsible of mycotoxin production. Phenolic extracts from edible plants were also active against $A$. flavus and aflatoxin production (Oliveira \& Furlong, 2008).

Weedy plants may also be used to prepare active extracts against mycotoxic fungi. Thembo et al. (2010) evaluated the antifungal activity of some weeds against some Aspergillus and Fusarium isolates. The authors reported that all organic extracts showed growth inhibitory activity against most isolates of the Fusarium spp., whereas no inhibition of the Aspergillus spp. was observed. A common weed of arable land and gardens in most parts of Europe and the African continent is Solanum nigrum, a member of the Solanaceae family. The medicinal values of this plant as hepatoprotective, antimicrobial, antitumor, etc., are well documented (Atanu et al., 2011). Methanolic and ethanolic extracts of $S$. nigrum have been previously tested in vitro for their antifungal activity against some Aspergillus and Fusarium species with ambiguous results (Mohamed et al., 1996; Harisankar et al., 2011; Zubarr et al., 2011; Abbas at al., 2014). In the present study, the potential of an aqueous crude extract from $S$. nigrum lyophilized leaves for inhibiting the growth of some mycotoxigenic fungi was evaluated by using in vitro techniques. The aqueous extract was prepared by following the procedures described by Musto et al. (2014), who reported that the extract was active against Penicillium digitatum non only in vitro, but also in vivo preinfection conditions on lemons wound-inoculated with $P$. digitatum. Moreover, the authors highlighted that their important results were obtained by using water, which is not toxic as other solvents (e.g. methanol or ethanol) and does not interfere with the bioassays.

\section{MATERIALS AND METHODS}

\section{Extract preparation}

Fresh leaves of $S$. nigrum were washed, lyophilized $\left(-53^{\circ} \mathrm{C}\right.$, $0.250 \mathrm{mbar}$ pressure) for $24 \mathrm{~h}$ by using a freeze dry system (Model Freezone 18, Labconco, Kansas City, MI, USA), and then powdered with a laboratory blender (Model 7010S, Waring Laboratory, New Hartford, CT, USA) for $30 \mathrm{~s}$. To prepare the extract, 10 grams of lyophilized powder were poured into $150 \mathrm{ml}$ of boiling double-distilled water $\left(\mathrm{ddH}_{2} \mathrm{O}\right)$. After $24 \mathrm{~h}$ in the dark under agitation, the mixture was clarified by centrifugation (at 20,000 rpm for $30 \mathrm{~min}$ ) and the supernatant filtered through Whatman No. 4 paper. The obtained extract was finally sterilized through filter membrane $(0.22 \mu \mathrm{m})$ before use.

\section{Phytochemical screening}

The presence of some phytochemical compounds was evaluated by using the protocols of Trease et al. (1989) and Pradhan et al. (2010), and modified by Musto et al. (2014).

Alkaloids. $5 \mathrm{ml}$ of the extract was treated first with $2 \mathrm{ml}$ of $\mathrm{HCl}$, and then with $1 \mathrm{ml}$ of Dragendroff's reagent. An orange or red precipitate indicated the presence of alkaloids.

Flavonoids. $1 \mathrm{ml}$ of the extract was treated with few drops of $2 \% \mathrm{NaOH}$ to produce an intense yellow colour. After adding few drops of dilute $\mathrm{HCl}$, the extract became colourless if it contained flavonoids.

Glycosides. $1 \mathrm{ml}$ of the extract was treated first with $2 \mathrm{ml}$ of $\mathrm{CH}_{3} \mathrm{COOH}$ mixed with few drops of $\mathrm{FeCl}_{3}$, and then with $1 \mathrm{ml}$ of $\mathrm{H}_{2} \mathrm{SO}_{4}$. Formation of a reddish brown colour at the junction of two layers and the bluish green colour in the upper layer indicated the presence of glycosides.

Saponins. $1 \mathrm{ml}$ extract was first diluted with $5 \mathrm{ml}$ of dd $\mathrm{H}_{2} \mathrm{O}$, and then agitated for $15 \mathrm{~min}$. The formation of at least $1 \mathrm{~cm}$ layer of foam indicated the presence of saponins.

Steroids. $1 \mathrm{ml}$ of the extracts was treated first with $10 \mathrm{ml}$ of $\mathrm{CHCl}_{3}$, and then with $10 \mathrm{ml}$ of $\mathrm{H}_{2} \mathrm{SO}_{4}$. A red colour in the upper layer and a yellow colour in $\mathrm{H}_{2} \mathrm{SO}_{4}$ layer indicated the presence of steroids.

Tannins. $1 \mathrm{ml}$ of the extract was first diluted with $4 \mathrm{ml}$ of $\mathrm{ddH}_{2} \mathrm{O}$, and then treated with few drops of $10 \% \mathrm{FeCl}_{3}$. Formation of a blue/green colour indicated the presence of tannins.

Terpenoids. $5 \mathrm{ml}$ of the extract was treated first with $2 \mathrm{ml}$ of $\left(\mathrm{CH}_{3} \mathrm{CO}\right)_{2} \mathrm{O}$, and then with $2 \mathrm{ml}$ of $\mathrm{CHCl}_{3}$; finally, $2 \mathrm{ml}$ of $\mathrm{H}_{2} \mathrm{SO} 4$ were added. Formation of reddish violet colour indicated their presence in the extract.

Reducing sugars. $1 \mathrm{ml}$ of the extract was first treated with 5-8 drops of Fehling's solutions ( $\mathrm{A}$ and $\mathrm{B}$ ), and then heated in a water-bath. Formation of a red precipitate indicated the presence of sugars.

\section{Antifungal activity evaluation}

Fungal cultures. Five mycotoxin-producing fungi were used in this study (Table 1). The spores of each fungus were harvested by flooding the surface of 10 days-old cultures with sterile $0.85 \%$ saline containing $0.1 \%$ Tween 80 , and scraping the surface of colonies with glass rods. Spore suspensions were filtered through double-layered sterile cheesecloth, and the concentration was then adjusted to $10^{6}$ spores $/ \mathrm{ml}$. 
In vitro antifungal activity assays. Two kinds of agar diffusion tests were performed, the well diffusion (WD) and the paper disk diffusion (PD) test. In both tests, about $20 \mathrm{ml}$ of the Saboraud Dextrose Agar (SDA) was poured into Petri plates $(9 \mathrm{~cm})$ and allowed to solidify. For each test and for each fungus, ten SDA plates were prepared by spreading $0.1 \mathrm{ml}$ of the spore suspension $\left(10^{4}\right.$ spores $\left.\cdot \mathrm{ml}^{-1}\right)$ on each plate. In the WD test, 3 wells ( $6 \mathrm{~mm}$ diameter) were aseptically punched at equidistant points into the agar medium of each plate, and then filled with $100 \mu \mathrm{l}$ of the crude extract. In the PD test, 3 sterile papers disks (Whatman No. 4 paper, $5 \mathrm{~mm}$ diameter), previously immersed in the crude extract and allowed to dry, were placed at equidistant points on agar surface of each plate. In both tests, Amphotericin $\mathrm{B}$ and sterile $\mathrm{ddH}_{2} \mathrm{O}$ were used as positive and negative controls, respectively. After $72 \mathrm{~h}$ at $25^{\circ} \mathrm{C}$, the antifungal activity of the extract was evaluated by measuring the diameters of the growth inhibition zones around each well and disk. The experiments were carried out in triplicate.

\section{RESULTS AND DISCUSSION}

As shown in Table 2 , seven out of eight tested phytochemical compounds were found in the extract. In particular, the extract contained alkaloids, flavonoids, glycosides, saponins, steroids, tannins, and terpenoids. These results are consistent from the previous studies on S. nigrum extracts (Gogoi \& Islam 2012; Musto et al., 2014; Modilal et al., 2015; Singh \& Vidyasagar, 2015a, b). According to the authors, thanks to the wide range of biological activities of these compounds, the extract may be exploited for the development of novel biopesticides or phytopharmaceuticals.

The results from the in vitro antifungal activity assays (Table 3) showed that the aqueous extract was active, in both agar diffusion tests, against $A$. carbonarius (WD: $23.6 \mathrm{~mm}$; PD: $15.3 \mathrm{~mm}$ ) and P. expansum (WD: $22.1 \mathrm{~mm}$; PD: $15.1 \mathrm{~mm}$ ). The inhibitory activity of the extract against these two fungi was slightly lower than that of positive control: for $A$. carbonarius the difference between the inhibition zones ranged from 6.1 (WD) to 8.4 (PD) $\mathrm{mm}$, whereas for P. expansum the range was 4.7 (WD) - 6.9 (PD) $\mathrm{mm}$. A higher concentration of the extract would have been as effective as the positive control. In fact, previous studies (e.g. Ekwenye and Elegalam, 2005; Okigbo and Igwe, 2007; Okigbo et al., 2012) on antimicrobial activity of different plant extracts have shown that the inhibitory effects are highly dependent on their concentrations, with stronger inhibition occurring at higher concentrations.

No inhibition was instead observed against A. flavus, F. graminearum, and F. verticillioides. A previous study revealed
Table 1: List of mycotoxin-producing fungi used in this study

Fungus Source

Aspergillus carbonarius DSMZ

Aspergillus flavus var. flavus

ISPA

Fusarium graminearum Schwabe

ISPA

Fusarium verticillioides (Saccardo)

ISPA

Penicillium expansum link

ISPA

*DSMZ: German Culture Collection (DSMZ, Braunschweig, Germany);

ISPA: Culture collection of agro-food important toxigenic fungi of Institute of Sciences of Food Production (ISPA, CNR-National Research Council, Bari, Italy)

Table 2: Phytochemical constituents of $S$. nigrum extract Phytochemical compound Result*

Alkaloids

Flavonoids

Saponins

Steroids

Glycosides

Terpenoids

Tannins

Reducing sugars

${ }^{*}+/$-: Presence/absence of the compound

Table 3: Antifungal activity ${ }^{1}$ of $S$. nigrum extract against five mycotoxigenic fungal strains ${ }^{2}$

\begin{tabular}{|c|c|c|c|c|c|c|c|c|c|c|}
\hline & \multicolumn{2}{|c|}{ A.C. } & \multicolumn{2}{|c|}{ A.F. } & \multicolumn{2}{|c|}{ F.G. } & \multicolumn{2}{|c|}{ F.V. } & \multicolumn{2}{|c|}{ P.E. } \\
\hline & WD & PD & WD & PD & WD & PD & WD I & $\mathbf{P D}$ & WD & PD \\
\hline SNE & $23.6 \pm 0.7$ & $15.3 \pm 0.9$ & - & - & - & - & - & - & $22.1 \pm 0.9$ & $15.1 \pm 1.2$ \\
\hline PC & $29.7 \pm 0.5$ & $23.7 \pm 0.5$ & - & - & - & - & - & - & $26.8 \pm 0.7$ & $22.0 \pm 0.5$ \\
\hline NC & - & - & - & - & - & - & - & - & - & - \\
\hline
\end{tabular}

${ }^{1}$ The values are means ( \pm standard deviations) of zones of inhibitions measured in the agar well diffusion (WD) and the paper disk diffusion (PD) test. ${ }^{2}$ A.C.: A. carbonarius; A.F.: A. flavus; F.G.: F. graminearum;

F.V.: F. verticillioides; P.E.: P. expansum; $\mathrm{SNE}=$ S. nigrum extract; PC: Positive control (Amphotericin B); NC: Negative control; -: No fungal growth inhibition

that a methanolic extract of $S$. nigrum inhibited the growth of A. flavus (Harisankar et al., 2011). The authors also found a weak activity against F. verticillioides. However, Zubair et al. (2011) reported that a methanolic extract of $S$. nigrum leaves did not inhibit the growth of $A$. flavus and $A$. niger. Similarly, Mohamed et al. (1996) found an ethanolic extract of $S$. nigrum to be not active against $A$. niger. More recently, Abbas at al. (2014) reported that the growth of against $A$. niger, A. flavus, and $A$. fumigatus was inhibited by a methanolic extract of the dried powdered fruit of $S$. nigrum. Compared to our results, the different antifungal activity against some mycotoxigenic fungi described in the aforementioned studies, are probably related to the different type of solvent used in the extraction procedures (methanol vs. water), as well as to the part of the plant used as starting vegetal material (leaf vs. fruit). These aspects can play a crucial role in preparing plant extracts (Ncube et al., 2008; Das et al., 2010). Overall, our results further confirm the antifungal activity of S. nigrum (Mohamed et al., 1996; Mutu et al., 2006; Atanu et al., 2011; Yanar et al., 2011; Lin et al., 2011; Sun et al., 2012; Singh et al., 2015a, b), and suggest 
that the obtained aqueous extract is as effective as other plant antimicrobial compounds (Soliman \& Badeaa, 2002; Selvi et al., 2003; Rasooli \& Abyaneh 2004; Bansod \& Rai 2008; Oliveira \& Furlong, 2008; Nguefack et al., 2009; Vilela et al., 2009; Thembo et al., 2010; Morcia et al., 2012; Philippe et al., 2012) for inhibiting the growth of some mycotoxigenic fungi.

The antifungal activity exhibited by our aqueous extract is strictly related to the presence of its phytochemical constituents (Table 2). Among them, some steroidal alkaloids (e.g. solamargine, solasonine, solanine, and saponin) have been identified as active compounds exhibiting a strong antifungal activity (Muto et al., 2006; Zhou et al., 2006; Al-Fatimi et al., 2007; Lin et al., 2011). For instance, Lin et al. (2011) found degalactotigonin, a steroidal saponin, to be active against Alternaria brassicicola, the causative agent of cabbage black leaf spot disease. The antifungal activity of the extract may be also due to the other phytochemical constituents, such as naturally occurring phenolic compounds. In other plants, these compounds have been found important for inhibiting growth and toxin production by toxigenic fungi (Guiraud et al., 1995; Beekrum et al. 2003; Bisogno et al., 2007; Palumbo et al. 2007; Romero et al., 2009). For instance, the growth of $A$. carbonarius and OTA production may be inhibited by some phenolic compounds (e.g. caffeic acid, quercetin, and rutin), especially at higher concentrations (Romero et al., 2009).

The precise mechanisms by which the phytochemical constituents of the extract can inhibit fungal growth are not fully understood. da Cruz Cabral et al. (2013) have recently highlighted some aspects concerning the mode of action of plant-derived extracts on which most authors agree. With regard to saponins, Nishikawa et al. (1984) and Keukens et al. (1995) reported that these compounds are capable to complex with sterols in fungal cell membranes, causing a loss of membrane integrity. Similarly, phenolic compounds are thought to affect the permeability of cell walls, the release of intracellular constituents, and to interfere with membrane function (Al-Reza et al., 2010). Moreover, phenolic acids can inhibit mycotoxin formation, as they may counter the oxidative stress that triggers or enhances toxin production (Mahoney \& Molyneux 2004).

\section{CONCLUSIONS}

Results from the present study confirmed that $S$. nigrum is a good source of antimicrobial compounds. In particular, a crude aqueous extract from lyophilized leaves of S. nigrum is active against two out of five tested mycotoxin-producing fungi. These results are encouraging, since the extract was obtained by using water, a solvent characterized by low toxicity and capable of extracting several bioactive compounds. This confirms the effectiveness of the procedures (i.e. leaf lyophilisation and maceration with water) used to obtain the extract. However, the choice of adopting these procedures should be also considered as a limitation of this study, since the research was not specifically designed to evaluate the whole potential of S. nigrum for inhibiting the growth of mycotoxigenic fungi. In this regard, further studies are needed to evaluate some factors related to extraction procedures (e.g. solvents, extract concentrations, etc.), as well as to clarify how the compound(s) found in the extract acts against the fungi. Further research might also explore wheatear these compounds affect mycotoxin production.

\section{REFERENCES}

Abbas, K., U. Niaz, T. Hussain, M. A. Saeed, Z. Javaid, A. Idrees and S. Rasool. 2014. Antimicrobial activity of fruits of Solanum nigrum and Solanum xanthocarpum. Acta Pol. Pharm. 71: 415-421.

Al-Fatimi, M., M. Wurster, G. Schröder and U. Lindequist. 2007. Antioxidant, antimicrobial and cytotoxic activities of selected medicinal plants from Yemen. J. Ethnopharmacol. 111: 657-666.

Al-Reza, S. M., A. Rahman, Y. Ahmed and S. C. Kang. 2010. Inhibition of plant pathogens in vitro and in vivo with essential oil and organic extracts of Cestrum nocturnum L. Pestic. Biochem. Physiol. 96: 86-92.

Atanu, F. O., U. G. Ebiloma and E. I. Ajayi. 2011. A review of the pharmacological aspects of Solanum nigrum Linn. Biotechnol. Mol. Biol. Rev. 6: 001-007.

Bansod, S. and M. Rai 2008. Antifungal activity of essential oils from Indian medicinal plants against human pathogenic Aspergillus fumigatus and A. niger. World J. Med. Sci. 3: 81-88.

Beekrum, S., R. Govinden, T. Padayachee and B. Odhav. 2003. Naturally occurring phenols: A detoxification strategy for fumonisin B. Food Addit. Contam. 20: 490-493.

Bennett, J. W. and M. Klich. 2003. Mycotoxins. Clin. Microbiol. Rev. 16: 497-516.

Bisogno, F., L. Mascoti, C. Sanchez, F. Garibotto, F. Giannini, M. Kurina-Sanz and R. Enriz. 2007. Structure-antifungal activity relationship of cinnamic acid derivatives. J. Agric. Food. Chem. 55: 10635-10640.

CAST. 2003. Mycotoxins: Risks in Plant, Animal, and Human Systems. Task Force Report No. 139, Council for Agricultural Science and Technology, Ames.

da Cruz Cabral, L., V. F. Pinto and A. Patriarca. 2013. Application of plant derived compounds to control fungal spoilage and mycotoxin production in foods. Int. J. Food Microbiol. 166: 1-14.

Das, K., R. K. S. Tiwari and D. K. Shrivastava. 2010. Techniques for evaluation of medicinal plant products as antimicrobial agent: Current methods and future trends. J. Med. Plants Res. 4: 104111.

Didwania, N. 2014. Mycotoxins: A review of toxicity, metabolism and biological approaches to counteract the production in food. MR Int. J. Eng. Technol. 6: 38-42.

Ekwenye, U. N. and N. N. Elegalam. 2005. Antibacterial activity of ginger (Zingiber officinale Roscoe and Garlic (Allium sativum L.) 
extracts on Escherichia coli and Salmonella typhi. Int. J. Mol. Adv. Sci. 1: 411-416.

Gogoi, P. and M. Islam. 2012. Phytochemical screening of Solanum nigrum L. and S. myriacanthus dunal from districts of upper Assam, India. IOSR J. Pharm. 2: 455-459.

Guiraud, P., R. Steiman, F. Seigle-Murandi and J. Benoit-Guyod. 1995. Comparison of the toxicity of various lignin-related phenolic compounds toward selected fungi perfecti and fungi imperfecti. Ecotoxicol. Environ. Saf. 32: 29-33.

Harisankar, G., P. Suthan, V. Joseph and A. J. Huxley. 2011. Antimicrobial bustle of selected yercaud medicinal plants against commercially important human pathogens. J. Basic. Appl. Biol. 5: 48-52.

Juglal, S., R. Govinden and B. Odhav. 2002. Spice oils for the control of co-occurring mycotoxin-producing fungi. J. Food Prot. 65: 683-687.

Kabak, B., A. D. Dobson and I. I. L. Var. 2006. Strategies to prevent mycotoxin contamination of food and animal feed: A review. Crit. Rev. Food Sci. Nutr. 46: 593-619.

Keukens, E. A., T. de Vrije, C. van den Boom, P. de Waard, H. H. Plasman, F. Thiel, V. Chupin, W. M. Jongen and B. de Kruijff. 1995. Molecular basis of glycoalkaloid induced membrane disruption. Biochim. Biophys. Acta. 1240: 216-228.

Lin, T. C., M. C. Fan, S. Y. Wang and J. W. Huang. 2011. Identification of the Solanum nigrum extract component involved in controlling cabbage black leaf spot disease. J. Agric. Food Chem. 59: 16671672.

Mahoney, N. and Molyneux R. 2004. Phytochemical inhibition of aflatoxigenicity in Aspergillus flavus by constituents of walnut (Juglans regia). J. Agric. Food Chem. 52: 1882-1889.

Modilal, M. R. D., R. Anandan, R. Sindhu and M. N. Logeshwari. 2015. Screening of Solanum nigrum for its phytochemical and antimicrobial activity against respiratory tract pathogens. Int. J. Pure Appl. Zool. 3: 210-215.

Mohamed, S., S. Saka, S. H. Elsharkawy, A. M. Ali and S. Muid. 1996. Antimycotic screening of 58 Malaysian plants against plant pathogens. Pestic. Sci. 47: 259-264.

Morcia, C., M. Malnati and V. Terzi. 2012. In vitro antifungal activity of terpinen-4-ol, eugenol, carvone, 1, 8-cineole (eucalyptol) and thymol against mycotoxigenic plant pathogens. Food Addit. Contam. Part A. 29: 415-422.

Musto, M., G. Potenza and F. Cellini. 2014. Inhibition of Penicillium digitatum by a crude extract from Solanum nigrum leaves. Biotechnol. Agron. Soc. Environ. 18: 174-180.

Muto, M., V. Mulabagal, H. C. Huang, H. Takahashi, H. S. Tsay and J. W. Huang. 2006. Toxicity of black nightshade (Solanum nigrum) extracts on Alternaria brassicicola, causal agent of black leaf spot of Chinese cabbage (Brassica pekinensis). J. Phytopathol. 154: 45-50.

Ncube, N., S. A. J. Afolayan and A. I. Okoh. 2008. Assessment techniques of antimicrobial properties of natural compounds of plant origin: Current methods and future trends. Afr. J. Biotechnol. 7: 1797-1806.

Nguefack, J., J. B. L. Dongmo, C. D. Dakole, V. Leth, H. F. Vismer, J. Torp, E. F. N. Guemdjom, M. Mbeffo, O. Tamgue and D. Fotio. 2009. Food preservative potential of essential oils and fractions from Cymbopogon citratus, Ocimum gratissimum and Thymus vulgaris against mycotoxigenic fungi. Int. J. Food Microbiol. 131: 151-156.

Nishikawa, M., S. Nojima, T. Akiyama, U. Sankawa and K. Inoue. 1984. Interaction of digitonin and its analogs with membrane cholesterol. J. Biochem. 96: 1231-1239.
Okigbo, R. N. and D. I. Igwe. 2007. The antimicrobial effects of Piper guineense "Uziza" and Phyllantus amarus "ebe benizo" on Candida albicans and Streptococcus faecalis. Acta Microbiol. Immunol. Hung. 54: 353-366.

Okigbo, R. N., C. A. Anukwuorji and C. T. Eguae 2012. Control of microorganisms causing the deterioration of yam chips with Vernonia amygdalina (L.) and Zingiber officinale (L.). Niger. J. Mycol. 5: 1-7.

Oliveira, M. D. S. and E. B. Furlong. 2008. Screening of antifungal and antimycotoxigenic activity of plant phenolic extracts. World Mycotoxin J. 1: 139-146.

Palumbo, J., T. O'Keeffe and N. Mahoney 2007. Inhibition of ochratoxin A production and growth of Aspergillus species by phenolic antioxidant compounds. Mycopathologia. 164: 241248.

Peraica, M., B. Radic, A. Lucic and M. Pavlovic. 1999. Toxic effects of mycotoxins in humans. Bull. World Health Organ. 77: 754-766.

Philippe, S., F. Souaïbou, A. Guy, D. T. Sébastien, Y. Boniface, A. Paulin, Y. Issaka and S. Dominique. 2012. Chemical composition and antifungal activity of essential oil of fresh leaves of Ocimum gratissimum from Benin against six mycotoxigenic fungi isolated from traditional cheese wagashi. Res. J. Biological. Sci. 1: 22-27.

Pitt, J. I. 2000. Toxigenic fungi and mycotoxins. Br. Med. Bull. 56: 184-192.

Pradhan, P., L. Joseph, M. George, N. Kaushik and R. Chulet. 2010. Pharmacognostic, phytochemical and quantitative investigation of Saraca asoca leaves. J. Pharm. Res. 3: 776-780.

Rasooli, I, and M. R. Abyaneh. 2004. Inhibitory effects of Thyme oils on growth and aflatoxin production by Aspergillus parasiticus. Food Control. 15: 479-483.

Razzaghi-Abyaneh, M., M. Shams-Ghahfarokhi, T. Yoshinari, M. B. Rezaee, K. Jaimand, H. Nagasawa and S. Sakuda 2008. Inhibitory effects of Satureja hortensis L. essential oil on growth and aflatoxin production by Aspergillus parasiticus. Int. J. Food Microbiol. 123: 228-233.

Richard, J. L. 2007. Some major mycotoxins and their mycotoxicoses An overview. Int. J. Food Microbiol. 119: 3-10.

Romero, S. M., M. R. Alberto, M. C. M. De Nadra and G. Vaamonde. 2009. Inhibition of growth and ochratoxin A biosynthesis in Aspergillus carbonarius by flavonoid and non-flavonoid compounds. Mycotoxin Res. 25: 165-170.

Selvi, A. T., G. S. Joseph and G. K. Jayaprakasha 2003. Inhibition of growth and aflatoxin production in Aspergillus flavus by Garcinia indica extract and its antioxidant activity. Food Microbiol. 20: 455-460.

Singh, P. S. and G. M. Vidyasagar. 2015a. Antifungal screening of 61 folkloric medicinal plant extracts against dermatophytic fungi Trichophyton rubrum. J. App. Pharm. Sci. 5: 38-44.

Singh, S. and G. M. Vidyasagar. 2015b. Antimycotic activity of low polar petroleum ether and interpolar methanolic young leaf extracts of Solanum nigrum L. Int. Lett. Nat. Sci. 4: 47-56.

Soliman, K. M. and R. I. Badeaa 2002. Effect of oil extracted from some medicinal plants on different mycotoxigenic fungi. Food Chem. Toxicol. 40: 1669-1675.

Sun, Y., Y. Zhao, L. Wang, H. Lou and A. Cheng. 2012. Cloning and expression analysis of squalene synthase, a key enzyme involved in antifungal steroidal glycoalkaloids biosynthesis from Solanum nigrum. Drug Discov. Ther. 6: 242-248.

Thembo, K. M., H. F. Vismer, N. Z. Nyazema, W. C. A. Gelderblom and D. R. Katerere. 2010. Antifungal activity of four weedy plant extracts against selected mycotoxigenic fungi. J. Appl. Microbiol. 109: 1479-1486. 
Trease, E. G. and W. C. Evans. 1989. Pharmacognosy. Balliere Tindall, London, p. 167-235.

Varga, J. and B. Tóth. 2005. Novel strategies to control mycotoxins in feeds: A review. Acta Vet. Hung. 53: 189-203.

Vilela, G. R., G. S. de Almeida, M. A. B. D'Arce, M. H. D. Moraes, J. O. Brito, M. F. D. da Silva, S. C. Silva, S. M. D. Piedade, M. A. Calori-Domingues and E. M. da Gloria. 2009. Activity of essential oil and its major compound, 1, 8-cineole, from Eucalyptus globulus Labill., against the storage fungi Aspergillus flavus Link and Aspergillus parasiticus Speare. J. Stored Prod. Res. 45: 108-111.

Yanar, Y., I. Kadioglu, A. Goeke, I. Demirta, N. Gören, H. Çam and M.
Whalon. 2011. In vitro antifungal activities of 26 plant extracts on mycelial growth of Phytophthora infestans (Mont.) de Bary. Afr. J. Biotechnol. 10: 2625-2629.

Zain, M. E. 2011. Impact of mycotoxins on humans and animals. J. Saudi Chem. Soc. 15: 129-144.

Zhou, X., X. He, G. Wang, H. Gao, G. Zhou, W. Ye and X. Yao. 2006. Steroidal saponins from Solanum nigrum. J. Nat. Prod. 69: 1158-1163.

Zubair, M., K. Rizwan, N. Rasool, N. Afshan, M. Shahid and V. U. Ahmed. 2011. Antimicrobial potential of various extract and fractions of leaves of Solanum nigrum. Int. J. Phytomed. 3: 63-67. 